\title{
Nitric Oxide Signaling in Pain and Nociceptor Sensitization in the Rat
}

\author{
K. O. Aley, Gordon McCarter, and Jon D. Levine \\ Departments of Anatomy, Medicine, and Oral Surgery, Division of Neuroscience, and National Institutes of Health Pain \\ Center (UCSF), University of California at San Francisco, San Francisco, California 94143-0452
}

\begin{abstract}
We investigated the role of nitric oxide (NO) in inflammatory hyperalgesia. Coinjection of prostaglandin $\mathrm{E}_{2}\left(\mathrm{PGE}_{2}\right)$ with the nitric oxide synthase (NOS) inhibitor $N^{G}$-methyl-L-arginine ( $L$ NMA) inhibited $\mathrm{PGE}_{2}$-induced hyperalgesia. L-NMA was also able to reverse that hyperalgesia. This suggests that NO contributes to the maintenance of, as well as to the induction of, $\mathrm{PGE}_{2}$-induced hyperalgesia. Consistent with the hypothesis that the $\mathrm{NO}$ that contributes to $\mathrm{PGE}_{2}$-induced sensitization of primary afferents is generated in the dorsal root ganglion (DRG) neurons themselves, L-NMA also inhibited the $\mathrm{PGE}_{2}$-induced increase in tetrodotoxin-resistant sodium current in patchclamp electrophysiological studies of small diameter DRG neurons in vitro. Although NO, the product of NOS, often activates guanylyl cyclase, we found that $\mathrm{PGE}_{2}$-induced hyperalgesia was not inhibited by coinjection of $1 \mathrm{H}-[1,2,4]$ oxadiazolo[4,3a]quinoxalin-1-one (ODQ), a guanylyl cyclase inhibitor. We then tested whether the effect of $\mathrm{NO}$ depended on interaction with the adenylyl cyclase-protein kinase $A(P K A)$ pathway, which is known to mediate $\mathrm{PGE}_{2}$-induced hyperalgesia. L-NMA inhibited hyperalgesia produced by 8-bromo-cAMP (a stable membrane permeable analog of cAMP) or by forskolin (an adenylyl cyclase activator). However, L-NMA did not inhibit hyperalgesia produced by injection of the catalytic subunit of PKA. Therefore, the contribution of $\mathrm{NO}$ to $\mathrm{PGE}_{2}$-induced hyperalgesia may occur in the CAMP second messenger pathway at a point before the action of PKA.
\end{abstract}

Tissue injury results in hyperalgesic pain (tenderness), probably the most common presenting clinical symptom. This important phenomenon is believed to be attributable, in great part, to sensitization of primary afferent nociceptors so that they respond at a lower stimulus intensity and with greater number of action potentials. Inflammatory mediators have been implicated in producing this sensitization and hyperalgesia. Of these, prostaglandins are well established as mediators of mechanical hyperalgesia in both animals and humans (Collier and Schneider, 1972; Moncada et al., 1975; Ferreira et al., 1978) and of sensitization of primary afferent nociceptors (Martin et al., 1987; Schaible and Schmidt, 1988; Davis et al., 1993; Rueff and Dray, 1993). The inflammatory mediator prostaglandin $\mathrm{E}_{2}\left(\mathrm{PGE}_{2}\right)$ is thought to act

Received April 23, 1998; revised June 12, 1998; accepted June 17, 1998.

This work was supported by National Institutes of Health Grant NS21647. We thank Dr. David Bredt for many discussions about NO/cGMP signaling and Drs. David Reichling and Kimberly Tanner for their careful scrutiny of this manuscript.

Correspondence should be addressed to Dr. Jon D. Levine, National Institutes of Health Pain Center (UCSF), C-522 Box 0452, University of California at San Francisco, San Francisco, CA 94143-0452.

Copyright (C) 1998 Society for Neuroscience $0270-6474 / 98 / 187008-07 \$ 05.00 / 0$
We next performed experiments to test whether administration of exogenous NO precursor or donor could mimic the hyperalgesic effect of endogenous NO. Intradermal injection of either the NOS substrate L-arginine or the NO donor 3-(4morphinolinyl)-sydnonimine hydrochloride (SIN-1) produced hyperalgesia. However, this hyperalgesia differed from $\mathrm{PGE}_{2}$ induced hyperalgesia, because it was independent of the cAMP second messenger system and blocked by the guanylyl cyclase inhibitor ODQ. Therefore, although exogenous NO induces hyperalgesia, it acts by a mechanism different from that by which endogenous $\mathrm{NO}$ facilitates $\mathrm{PGE}_{2}$-induced hyperalgesia. Consistent with the hypothesis that these mechanisms are distinct, we found that inhibition of $\mathrm{PGE}_{2}$-induced hyperalgesia caused by L-NMA could be reversed by a low dose of the NO donor $\mathrm{SIN}-1$. The following facts suggest that this dose of SIN-1 mimics a permissive effect of basal levels of $\mathrm{NO}$ with regard to $\mathrm{PGE}_{2}$-induced hyperalgesia: (1) this dose of SIN-1 does not produce hyperalgesia when administered alone, and (2) the effect was not blocked by ODQ.

In conclusion, we have shown that low levels of NO facilitate cAMP-dependent $\mathrm{PGE}_{2}$-induced hyperalgesia, whereas higher levels of NO produce a cGMP-dependent hyperalgesia.

Key words: hyperalgesia; nitric oxide; pain; primary afferent nociceptor; prostaglandin E2; protein kinase A; tetrodotoxinresistant sodium current

directly on the peripheral terminals of primary afferent nociceptors to produce hyperalgesia (Taiwo and Levine, 1989), to sensitize nociceptors in vitro (England et al., 1996; Gold et al., 1996a), and to enhance tetrodotoxin-resistant voltage-gated sodium current (TTX-R $\mathrm{I}_{\mathrm{Na}}$ ). Previous work in our laboratory suggests that $\mathrm{PGE}_{2}$-induced sensitization of nociceptors is mediated by the adenylyl cyclase-cAMP-protein kinase A (PKA) second messenger system. For example, agents that inhibit adenylyl cyclase, as well as those that inhibit PKA, attenuate $\mathrm{PGE}_{2}$-induced hyperalgesia (Taiwo and Levine, 1989, 1991; Khasar et al., 1995). $\mathrm{PGE}_{2}$ is a key mediator of inflammatory hyperalgesia.

A number of observations suggest that in the periphery nitric oxide (NO) also acts as a pronociceptive mediator (Moulton, 1996; Robbins and Grisham, 1997; Wallace and Chin, 1997). Intracutaneous injections of NO precursors evoke pain in humans (Houlthusen and Arndt, 1994, 1995). That NO is generated within nociceptors is suggested by these observations: (1) neuronal nitric oxide synthase-like immunoreactivity (nNOS-LI) is expressed in small- and medium-diameter dorsal root ganglion (DRG) neurons in rat and monkey (Zhang et al., 1993; Qian et 


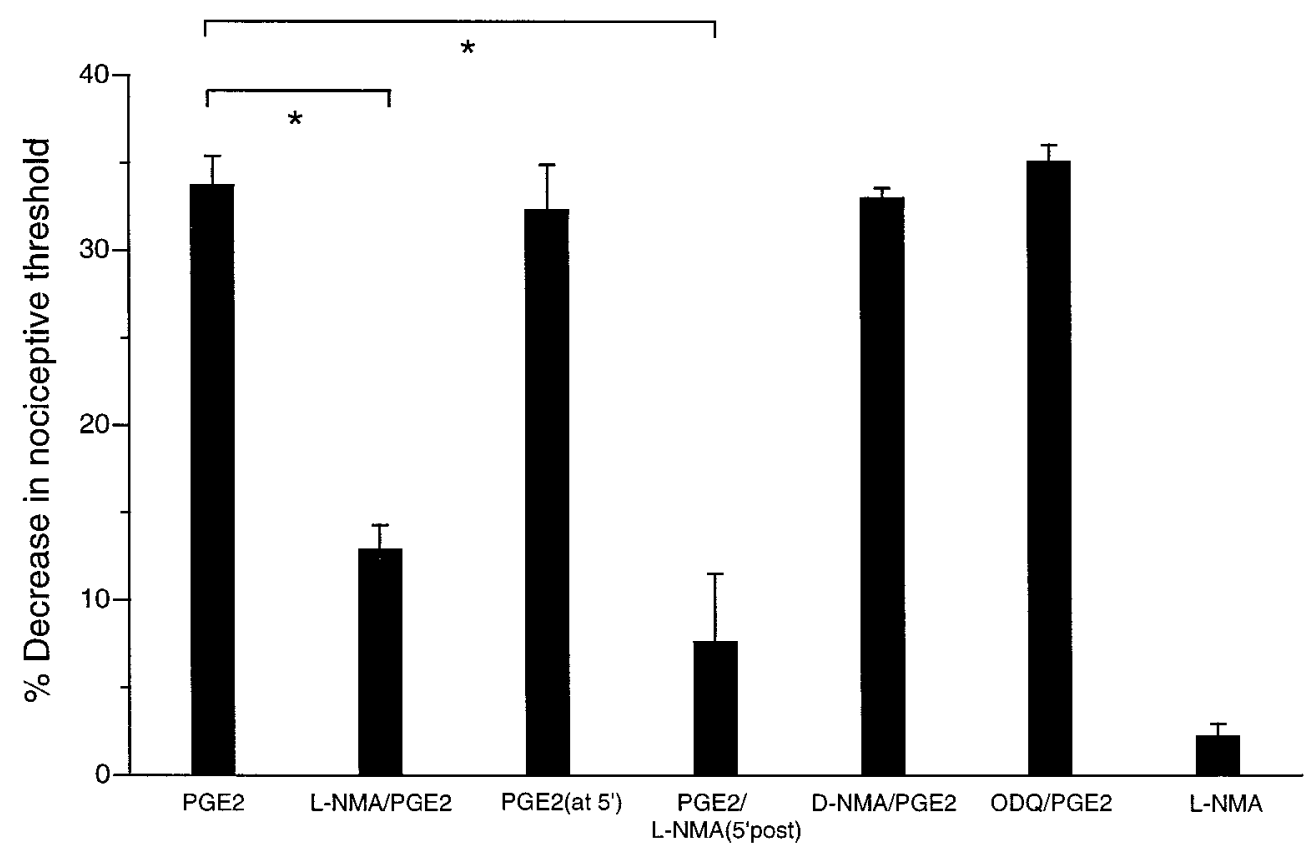

Figure 1. Reduction of mechanical nociceptive threshold (hyperalgesia) produced by $\mathrm{PGE}_{2} 15$ min after injection (PGE2) (100 ng; $n=12)$, L-NMA (1 $\mu \mathrm{g} ; n=6)$ plus $\mathrm{PGE}_{2}(L-N M A / P G E 2)$ $(n=12 ; p<0.05), \mathrm{PGE}_{2} 5 \mathrm{~min}$ after injection $\left[P G E 2\left(5^{\prime}\right)\right](n=6)$, L-NMA 5 min after $\mathrm{PGE}_{2}$ (PGE2/L-NMA5'post) $(n=6 ; p<0.05)$, D-NMA $(10 \mu \mathrm{g})$ plus $\mathrm{PGE}_{2}(D-N M A / P G E 2)(n=6), \mathrm{ODQ}(1$ $\mu \mathrm{g})$ plus $\mathrm{PGE}_{2}(O D Q / P G E 2)(n=6)$, and $L-N M A(n=6)$ on mechanical pawwithdrawal threshold in rats. In this and subsequent figures, ${ }^{*} p<0.05$. Higher values indicate greater hyperalgesia. The data for one behavioral experimental group, $\mathrm{PGE}_{2}$, is repeated in more than one figure for ease of comparison. al., 1996); (2) NADPH-diaphorase activity (Vanhatalao et al., 1996) and nNOS-LI (Zhang et al., 1993; Majewski et al., 1995) are colocalized in some DRG neurons with substance P-LI (SP-LI) and calcitonin gene-related peptide-LI (CGRP-LI); and (3) NOS-LI is coexpressed in some DRG neurons with CGRP-LI or SP-LI (Zhang et al., 1993) and is greatly reduced in DRG neurons in neonatal rats treated with capsaicin (Ren and Ruda, 1995). NO is considered to play a role in the induction of nociception, because NOS-LI in lumbar DRG neurons is increased by noxious irritation of the bladder (Vizzard et al., 1996), by noxious stimulation with resiniferatoxin (Farkas-Szallasi et al., 1995; Vizzard et al., 1995), and by induction of neuropathic models of pain using sciatic nerve transection (Fiallos-Estrada et al., 1993; Zhang et al., 1993; Beesley, 1995) or by ligation of lumbar dorsal roots (Choi et al., 1996) or nerves (Steel et al., 1994). NO also contributes to withdrawal hyperalgesia in rats made tolerant to opioidinduced peripheral antinociception (Aley and Levine, 1997a,b). Furthermore, the NOS inhibitor $N^{\mathrm{G}}$-methyl-L-arginine (L-NMA) suppresses activity in lumbar dorsal roots originating from a sciatic neuroma (Wiesenfeld-Hallin et al., 1993). L-NMA also reduces thermal hyperalgesia produced by chronic constriction injury of the sciatic nerve or hindpaw inflammation (Moore et al., 1993; Thomas et al., 1996; Lawand et al., 1997). Clearly, there is abundant evidence that NO plays a role in nociceptive signaling. When studying NO, it is important to evaluate cGMP, because NO stimulates guanylyl cyclase, and many of the cellular effects of $\mathrm{NO}$ are the result of NO-induced increases in the level of cGMP (Jaffrey and Snyder, 1995). NO-donating compounds stimulate marked elevation of cGMP levels in cultured rat DRG neurons (Dymshitz and Vasko, 1994), and activation of NOS by the algesic agent bradykinin increases cGMP in rat DRG neurons (Harvey and Burgess, 1996).

Because interactions between inflammatory mediators have been reported and because there are interactions at the second messenger level, it is important to evaluate whether NO contributes to the prototype hyperalgesia and sensitization produced by $\mathrm{PGE}_{2}$. In this study, therefore, we tested such a contribution by NO to hyperalgesia produced by the inflammatory mediator
$\mathrm{PGE}_{2}$, and we investigated mechanisms underlying the induction of hyperalgesia by NO, which have not been well delineated.

\section{MATERIALS AND METHODS}

Animals. Experiments were performed on male Sprague Dawley rats (200-250 gm; Bantin-Kingman, Fremont, CA). Animals were housed in groups of two under a $12 \mathrm{hr}$ light/dark cycle. Food and water were available ad libitum. All behavioral testing was done between 10:00 A.M. and 4:00 P.M. Experiments were performed with the approval of the Institutional Animal Care Committee of the University of California at San Francisco.

Behavioral testing. The nociceptive flexion reflex was quantified with a Basil analgesymeter (Stoelting, Chicago, IL), which applies a linearly increasing mechanical force to the dorsum of the rat's hindpaw. Before the experiments, rats were exposed to the paw-withdrawal testing procedure for $3 \mathrm{hr}(1 \mathrm{hr} / \mathrm{d}$ for $3 \mathrm{~d})$. On the day of the experiment, rats were exposed to the same procedure for $1 \mathrm{hr}$, and the baseline threshold was determined as the mean of the six readings before the administration of the test agent (Aley and Levine, 1997a,b). The mean \pm SEM baseline threshold before treatments for the rats used in these experiments was $108.0 \pm 0.4 \mathrm{gm}(n=260)$. Mechanical threshold was redetermined at three time points $(15,20$, and $25 \mathrm{~min})$ after administration of a hyperalgesic agent. The mean of these three readings was considered to be the paw-withdrawal threshold because of hyperalgesic agent administration, and this value was used to calculate the percentage change from the baseline threshold for each paw. To determine the timing of onset of action of the hyperalgesic agents, the mechanical threshold was also measured at 1 min intervals for 5 min after their administration, whereas the time course was determined by measuring the mechanical threshold at 30-60 min intervals for 2-4 hr.

Drug administration. The following drugs used in this study were obtained from Sigma (St. Louis, MO): $\mathrm{PGE}_{2}$, L-arginine (L-Arg), D-arginine (D-Arg), L-NMA, $N^{\mathrm{G}}$-methyl-D-arginine (D-NMA), 8-bromocAMP, and 3-morpholino-sydnonimine (SIN-1). Forskolin, 2-p-(2carboxyethyl)phenethylamino-5'- $N$-ethylcarboxamido adenosine $\mathrm{HCl}$ (CGS21680), and ( \pm )-2-dipropylamino-8-hydroxy-1,2,3,4-tetrahydronaphthalene $\mathrm{HBr}$ (8-OH-DPAT) were obtained from Research Biochemicals (Natick, MA). WIPTIDE was obtained from Peninsula Laboratories (Belmont CA), and 1H-[1,2,4]oxadiazolo[4,3-a]quinoxalin-1one (ODQ) and protein kinase A catalytic subunit (PKACS) were obtained from Calbiochem (La Jolla, CA). The selection of the drug doses used in this study was based on dose-response curves determined during this and previous studies (Aley and Levine, 1997a,b). The stock solution of $\mathrm{PGE}_{2}(1 \mu \mathrm{g} / 2.5 \mu \mathrm{l})$ was prepared in $10 \%$ ethanol, and further dilutions were made in saline; the final concentration of ethanol was 
Figure 2. L-NMA reduces the $\mathrm{PGE}_{2}$-induced potentiation of TTX-R $\mathrm{I}_{\mathrm{Na}}$. TTX-R $\mathrm{I}_{\mathrm{Na}}$ was monitored by test pulses given every $20 \mathrm{sec}$. Voltage of the test pulse $(-20$ to $-5 \mathrm{mV})$ was selected for each neuron to give an approximately half-maximal current amplitude. One hundred micromolar D-NMA or L-NMA was included in the bath for $15 \mathrm{~min}$ before exposure to $1 \mu \mathrm{M} \mathrm{PGE}_{2}$. $\mathrm{PGE}_{2}$ typically causes a potentiation of TTX-R $\mathrm{I}_{\mathrm{Na}}$ in approximately half of cells tested (Gold et al., 1996a,b). Experiments were alternated between using the active and inactive enantiomers of the NOS inhibitor, and data from all neurons were used, including those in which the current was not affected by $\mathrm{PGE}_{2}$. Peak current amplitudes were normalized to mean of the baseline measurements.

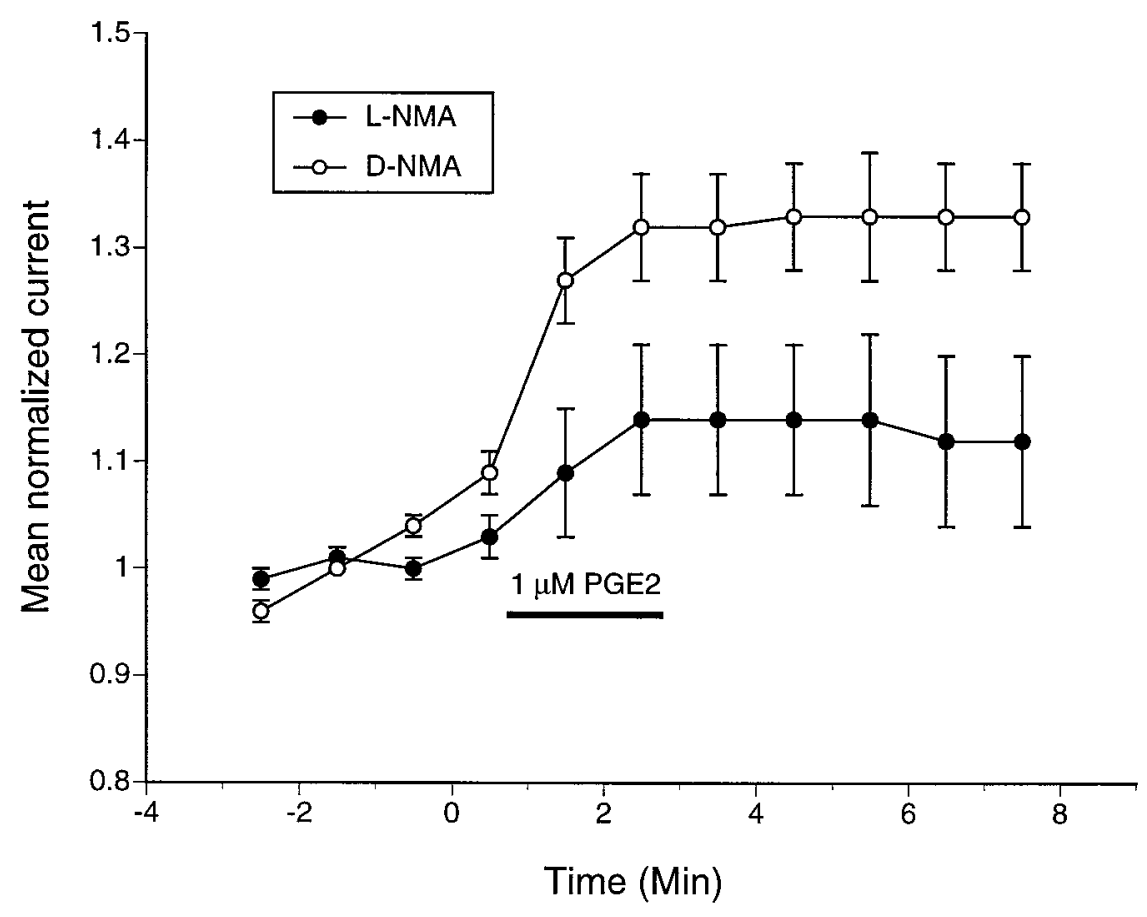

Figure 3. Reduction of the pawwithdrawal threshold by the $\mathrm{A}_{2}$ adenosine agonist $C G S 21680$ after injection $(1 \mu \mathrm{g} ; n=6)$, L-NMA plus CGS21680 $(L-N M A / C G S) \quad(n=6 ; p<0.05)$, $5^{-T_{1 A}}$ agonist $8-O H$-DPAT after injection $(1 \mu \mathrm{g} ; n=6)$, and L-NMA plus 8-OH-DPAT $(L-N M A / 8-O H)(n=6$; $p<0.05)$ on mechanical pawwithdrawal threshold in rats.

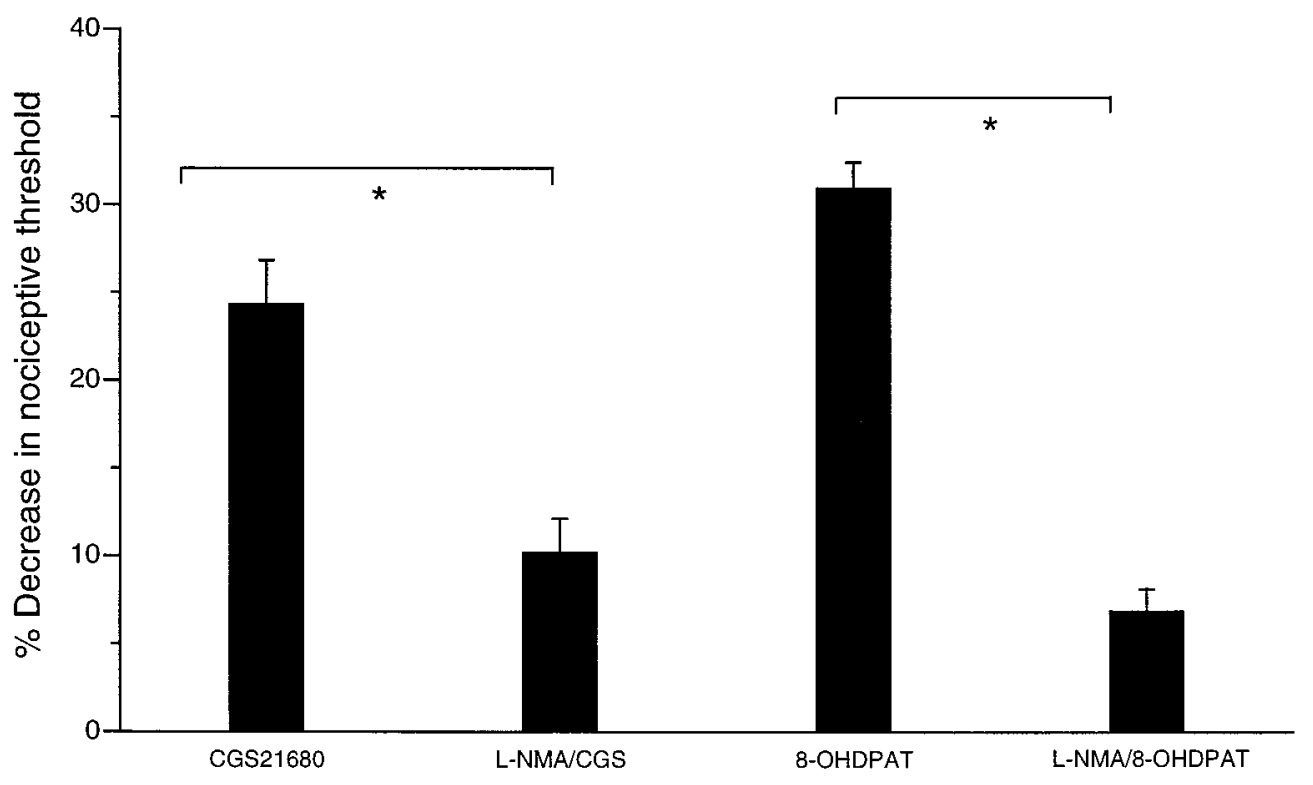

$\leq 1 \%$. 8-bromo-cAMP, L-NMA, D-NMA, PKACS, and WIPTIDE were dissolved in saline. ODQ was dissolved in DMSO and diluted with saline (final concentration of DMSO, 10\%). CGS21680 and 8-OH-DPAT were dissolved in deionized water. All drugs administered intradermally were in a volume of $2.5 \mu \mathrm{l} /$ paw. For test agents with low cell membrane permeability (i.e., WIPTIDE and PKACS), $2 \mu$ of distilled water was coinjected first, in the same syringe as the test agent to produce hypoosmotic shock and thus facilitate cell permeability (Taiwo and Levine, 1989; Khasar et al., 1995). When drug combinations were used, they were administered from the same syringe in such a way that the drug mentioned first reached the intradermal site first. Such combinations of agents were separated in the syringe by a small air bubble to prevent their mixing in the syringe. Whenever an inhibitor was included, it was injected first.

Cell culture and in vitro electrophysiology. Primary cultures of adult rat lumbar DRG neurons were prepared as described previously (Gold et al., 1996b). Culture medium consisted of minimal essential medium [University of California at San Francisco (UCSF) Cell Culture Facility] with $10 \%$ fetal bovine serum (Life Technologies, Gaithersburg, MD) and 1000
$\mathrm{U} / \mathrm{ml}$ each penicillin and streptomycin (UCSF Cell Culture Facility). Ganglia were dissected free, desheathed in cold culture medium, and then incubated for $2 \mathrm{hr}$ at $37^{\circ} \mathrm{C}$ in culture medium with $0.125 \%$ collagenase. After an additional $10 \mathrm{~min}$ digestion in $0.25 \%$ trypsin, cells were mechanically dispersed by trituration with a fire-polished Pasteur pipette. Cells were plated onto glass coverslips coated with laminin (Life Technologies) and poly-DL-ornithine (Sigma) and were maintained in culture medium with nerve growth factor (Life Technologies) at $37^{\circ} \mathrm{C}$ under $3 \%$ $\mathrm{CO}_{2}$. Neurons were used within $24 \mathrm{hr}$ of plating before appreciable outgrowth of neurites at a time when small diameter $(20-30 \mu \mathrm{m})$ neuronal cell bodies express properties of nociceptors (Gold et al., 1996b). Drugs were added via the bath, which continuously perfused the recording chamber at $1-2 \mathrm{ml} / \mathrm{min}$. Experiments were performed at room temperature $\left(21-24^{\circ} \mathrm{C}\right)$.

Whole-cell patch-clamp recordings were performed on small diameter $(<30 \mu \mathrm{m})$ neurons in 1-d-old cultures of dissociated DRGs from adult rats, using an Axopatch 200B amplifier with pClamp6 acquisition and stimulation programs (Axon Instruments, Foster City, CA). Data were low-pass-filtered at $5 \mathrm{kHz}$ and acquired at a sampling rate of $10 \mathrm{kHz}$. 


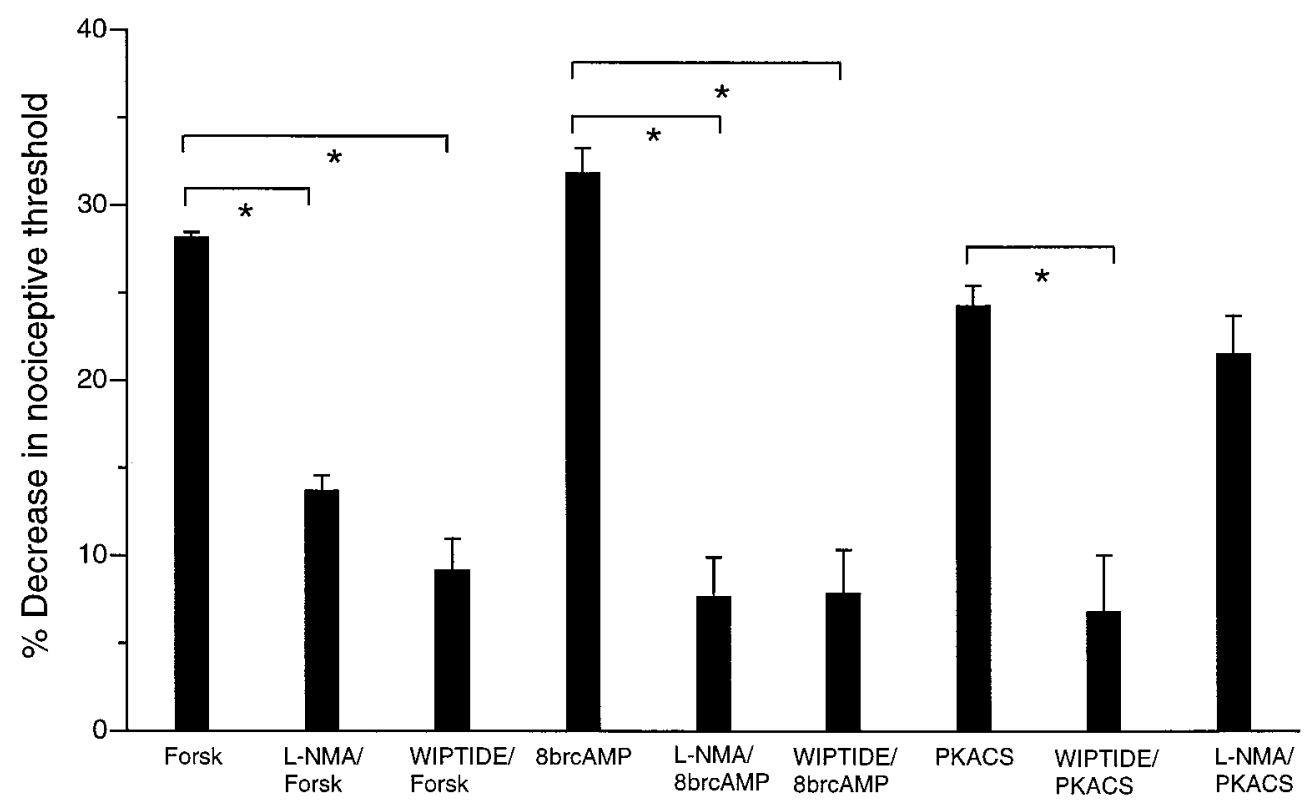

Figure 4. Reduction of the pawwithdrawal threshold by forskolin (10 $\mu \mathrm{g}) 5 \mathrm{~min}$ after injection (Forsk) $(n=$ 8), L-NMA plus forskolin ( $L-N M A$ / Forsk) $(n=6 ; p<0.05)$, WIPTIDE plus forskolin (WIPTIDE/Forsk) $(n=$ $10 ; p<0.05)$, 8-bromo-cAMP after injection (8brcAMP) $(1 \mu \mathrm{g} ; n=12)$, L-NMA plus 8-bromo-cAMP ( $L$-NMA) $8 b r c A M P)(n=8 ; p<0.05)$, WIPTIDE plus 8-bromo-cAMP (WIPTIDE/8brcAMP $)(n=6 ; p<0.05)$, PKACS (15 U; $n=12)$, WIPTIDE plus PKACS (WIPTIDE/PKACS) $(n=$ $6 ; p<0.05$ ), and L-NMA plus PKACS $(L-N M A / P K A C S)(n=6$; not statistically significant) on mechanical pawwithdrawal threshold in rats.

Voltage-clamp experiments were performed with 2-5 $\mathrm{M} \Omega$ electrodes filled with (in mM): $\mathrm{CsCl} 140, \mathrm{NaCl} 10, \mathrm{CaCl}_{2} 0.1, \mathrm{MgCl}_{2}$ 2, EGTA 11, HEPES 10, MgATP 2, and LiATP 1, pH adjusted to 7.2 with Tris base. Bath consisted of (in $\mathrm{mM}$ ): $\mathrm{NaCl} \mathrm{35,} \mathrm{tetraethylammonium} \mathrm{chloride} \mathrm{30,}$ choline chloride $65, \mathrm{CaCl}_{2} 0.5, \mathrm{MgCl}_{2} 5$, HEPES 10 , and glucose, $\mathrm{pH}$ adjusted to 7.4 with $\mathrm{NaOH}$, and osmolality adjusted to $325 \mathrm{mOsm}$ with sucrose. Tetrodotoxin (50 nM) was added to the bath. Capacitance and series resistance was compensated $(>80 \%)$, and leak subtraction was performed with a $\mathrm{P} / 4$ protocol. After obtaining a current-voltage relationship for TTX-R $\mathrm{I}_{\mathrm{Na}}$, a $25 \mathrm{msec}$ depolarizing test pulse was applied every $20 \mathrm{sec}$ to monitor the size of the current during the experiment. A voltage that produced approximately half of the maximal current activation was used for the test pulse, because the greatest increase in TTX-R I $\mathrm{I}_{\mathrm{Na}}$ produced by $\mathrm{PGE}_{2}$ is seen at this part of the current-voltage relationship. Experimental and control neurons were studied alternately on the same day for each comparison.

Statistical analysis. Data are presented as mean \pm SEM; statistical significance was determined by ANOVA followed by Scheffe's post hoc test; and $p<0.05$ was considered statistically significant.

\section{RESULTS}

\section{L-NMA, but not ODQ, blocks $\mathrm{PGE}_{\mathbf{2}}$ hyperalgesia}

We first determined whether $\mathrm{NO}$ contributes to $\mathrm{PGE}_{2}$-induced hyperalgesia and whether guanylyl cyclase is involved (Fig. 1). Injection of L-NMA (1 $\mu \mathrm{g})$, a competitive NOS inhibitor, preceding $\mathrm{PGE}_{2}$ in the same syringe significantly attenuated $\mathrm{PGE}_{2}-$ induced hyperalgesia to mechanical stimuli $(p<0.05)$. Injection of L-NMA $(1 \mu \mathrm{g}) 5 \mathrm{~min}$ after $\mathrm{PGE}_{2}$, when hyperalgesia is already well established (Ouseph et al., 1995), significantly reversed hyperalgesia. L-NMA alone had no effect on mechanical nociceptive threshold. The inactive stereoisomer of L-NMA, D-NMA (10 $\mu \mathrm{g})$, was without effect on $\mathrm{PGE}_{2}$-induced hyperalgesia. Injection of the guanylyl cyclase inhibitor ODQ $(1 \mu \mathrm{g})$ before $\mathrm{PGE}_{2}$ had no effect.

\section{L-NMA inhibits $P G E_{2}$-induced potentiation of TTX-R $I_{n a}$ in vitro}

$\mathrm{PGE}_{2}$ sensitizes cultured small diameter DRG neurons and potentiates TTX-R I $\mathrm{Na}_{\mathrm{Na}}$ (England et al., 1996; Gold et al., 1996a). We tested whether endogenous NO derived from the primary afferent is necessary for potentiation of TTX-R $\mathrm{I}_{\mathrm{Na}}$ by $P \mathrm{PE}_{2}$. One hundred micromolar L-NMA $(n=15)$ or D-NMA $(n=14)$ was added to the extracellular bath for $15 \mathrm{~min}$ before the application of $1 \mu \mathrm{M} \mathrm{PGE}_{2}$. The mean $\mathrm{PGE}_{2}$-induced increase in the size of peak TTX-R $\mathrm{I}_{\mathrm{Na}}$ elicited by a depolarizing voltage step was significantly smaller in the cells treated with L-NMA than in those treated with D-NMA $(p<0.05)$ (Fig. 2).

\section{L-NMA blocks hyperalgesia induced by CGS21680 and 8-OH-DPAT}

We tested whether NOS activity is required to produce hyperalgesia induced by other peripherally acting hyperalgesic agents. As shown previously (Taiwo and Levine, 1989, 1990, 1991; Taiwo et al., 1992), the intradermal injection of CGS21680 ( $\mathrm{A}_{2}$ adenosine receptor agonist; $1 \mu \mathrm{g})$ and 8 -OH-DPAT $\left(5 \mathrm{HT}_{1 \mathrm{~A}}\right.$ serotonergic agonist; $1 \mu \mathrm{g}$ ) produced mechanical hyperalgesia (Fig. 3). Injection of L-NMA $(1 \mu \mathrm{g})$ with CGS21680 and 8-OH-DPAT significantly attenuated the resulting hyperalgesia $(p<0.05)$ (Fig. 3), similar to its effect on $\mathrm{PGE}_{2}$-induced hyperalgesia.

\section{L-NMA blocks hyperalgesia induced by 8-bromo-cAMP and forskolin but not by PKACS}

To determine whether the contribution of NO to hyperalgesia is attributable to interaction of NO with the cAMP second messenger system and at what level in the cAMP second messenger pathway NO is required, we evaluated the effect of L-NMA on the hyperalgesia produced by different components of the pathway. Five minutes after the intradermal injection of 8-bromo-cAMP $(10 \mu \mathrm{g})$, forskolin $(10 \mu \mathrm{g})$, or PKACS (the catalytic subunit of PKA; $15 \mathrm{U})$, near-maximal mechanical hyperalgesia was present. Injection of L-NMA (1 $\mu \mathrm{g})$ before 8-bromo-cAMP and forskolin, but not PKACS, resulted in reduced hyperalgesia (Fig. 4). Injection of WIPTIDE inhibited PKACS hyperalgesia, as it did 8-bromo-cAMP and forskolin hyperalgesia, which indicates that the isolated catalytic subunit of PKA appears to produce hyperalgesia through the same catalytic action as PKA.

\section{Administration of NO donor or precursor induces hyperalgesia}

As shown in Figure 5, $A$ and $D$, intradermal injection of the NOS substrate L-Arg (10 ng to $10 \mu \mathrm{g}$ ) or the NO donor SIN-1 (10 ng to $40 \mu \mathrm{g}$ ) caused a dose-dependent decrease in the paw-withdrawal threshold. This hyperalgesia was inhibited by the guanylyl cyclase 


\section{$\underline{\text { L-Arginine }(10 \mu \mathrm{g})}$}
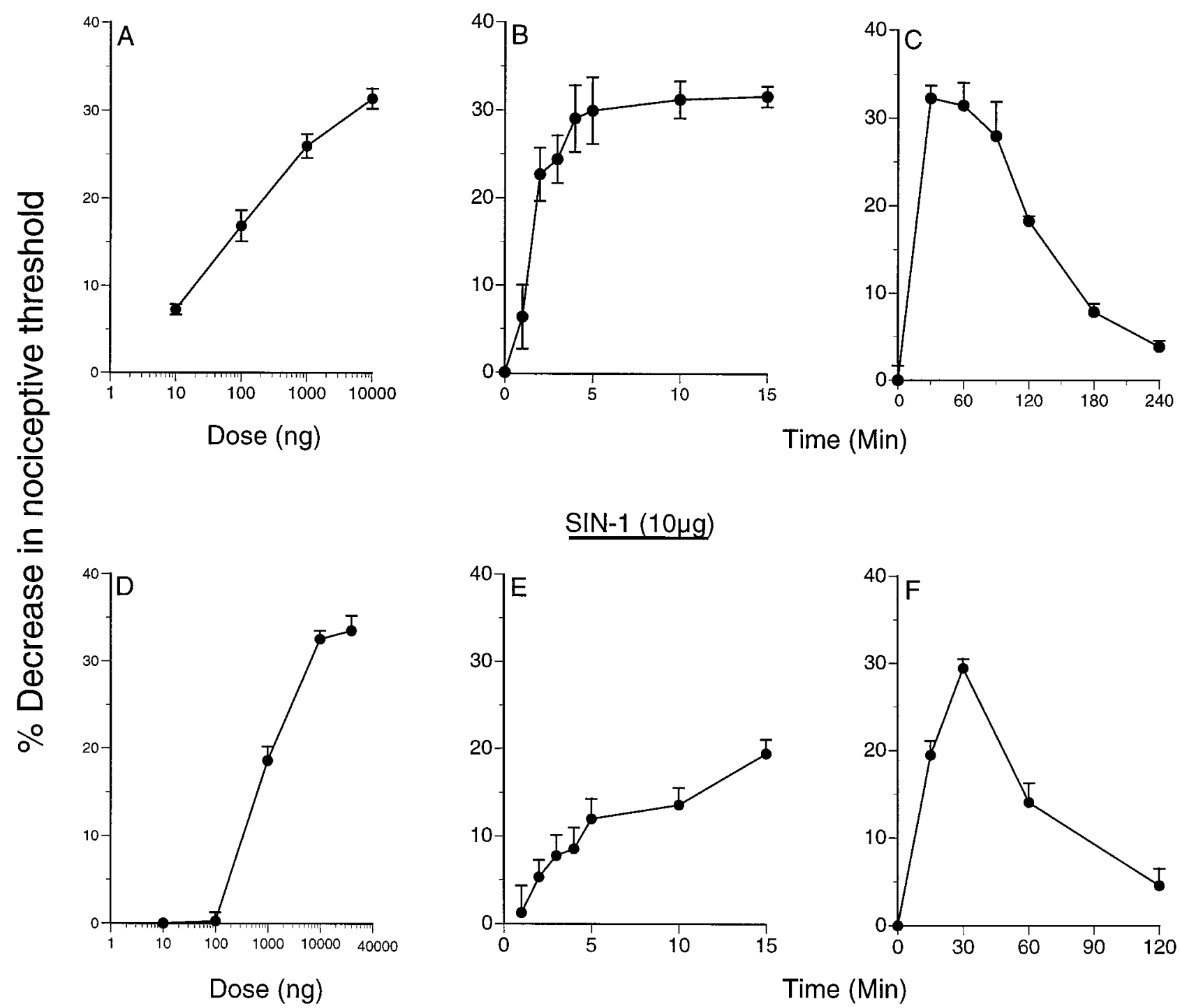

Time (Min)

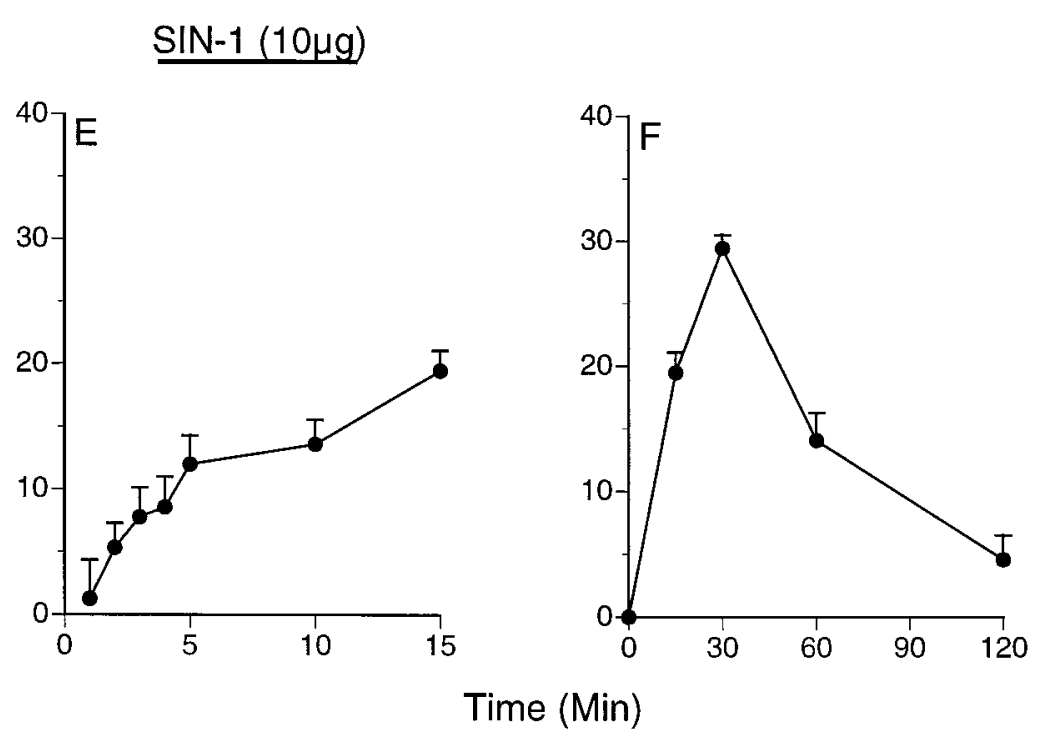

Figure 5. $A$, Dose-response curve for L-Arg-induced hyperalgesia $(n=6) . B$, Latency to onset of L-Arg-induced $(10 \mu \mathrm{g})$ mechanical hyperalgesia $(n=$ 6). $C$, Time course of L-Arg-induced mechanical hyperalgesia $(n=6)$. $D$, Dose-response curve of SIN-1-induced hyperalgesia $(n=6)$. $E$, Latency to onset of SIN-1-induced hyperalgesia $(10 \mu \mathrm{g} ; n=6)$. $F$, Time course of SIN-1-induced hyperalgesia $(n=8)$.

inhibitor ODQ but was unaffected by the PKA inhibitor WIPTIDE (Fig. 6A). This hyperalgesic action of NO contrasts with the guanylyl cyclase-independent mechanism by which NO facilitates $\mathrm{PGE}_{2}$-induced hyperalgesia (Fig. $6 B$ ). In control experiments, D-Arg did not induce hyperalgesia (Fig. 6A).

\section{Exogenous sources of NO can reconstitute the facilitatory effect of endogenous $\mathrm{NO}$ on $\mathrm{PGE}_{2}$-induced hyperalgesia}

We tested whether NO from exogenous sources can mimic the ability of endogenous $\mathrm{NO}$ to facilitate $\mathrm{PGE}_{2}$-induced hyperalgesia. To inhibit endogenous NO production, L-NMA was coinjected into the paw with $\mathrm{PGE}_{2}$, which reduced the $\mathrm{PGE}_{2}$-induced decrease in paw-withdrawal threshold by $\sim 62 \%$ (Fig. 1). As shown in Figure $6 \mathrm{~B}$, coinjection of the NO donor compound SIN-1 with L-NMA and $\mathrm{PGE}_{2}$ restored the $\mathrm{PGE}_{2}$-induced decrease in paw-withdrawal threshold to a value similar to that observed when endogenous NOS was not inhibited (i.e., in the absence of L-NMA). The $100 \mathrm{ng}$ dose of SIN-1 that facilitated $\mathrm{PGE}_{2}$-induced hyperalgesia was insufficient to induce hyperalgesia by itself (Fig. 5D). To further preclude the possibility that NO-induced (cGMP-dependent) hyperalgesia played a role in this reconstitution experiment, the guanylyl cyclase inhibitor ODQ was coinjected with $\mathrm{PGE}_{2}$, L-NMA, and SIN-1.

\section{DISCUSSION}

In this study, we found that NO, but not cGMP, contributes to initiation and maintenance of hyperalgesia and sensitization produced by the inflammatory mediator $\mathrm{PGE}_{2}$. We also found that the independent hyperalgesia produced by NO depends on cGMP and may require a higher concentration than that for facilitation of $\mathrm{PGE}_{2}$ hyperalgesia and sensitization. The reduction in $\mathrm{PGE}_{2}$-induced potentiation of TTX-R $\mathrm{I}_{\mathrm{Na}}$ in L-NMA treated 

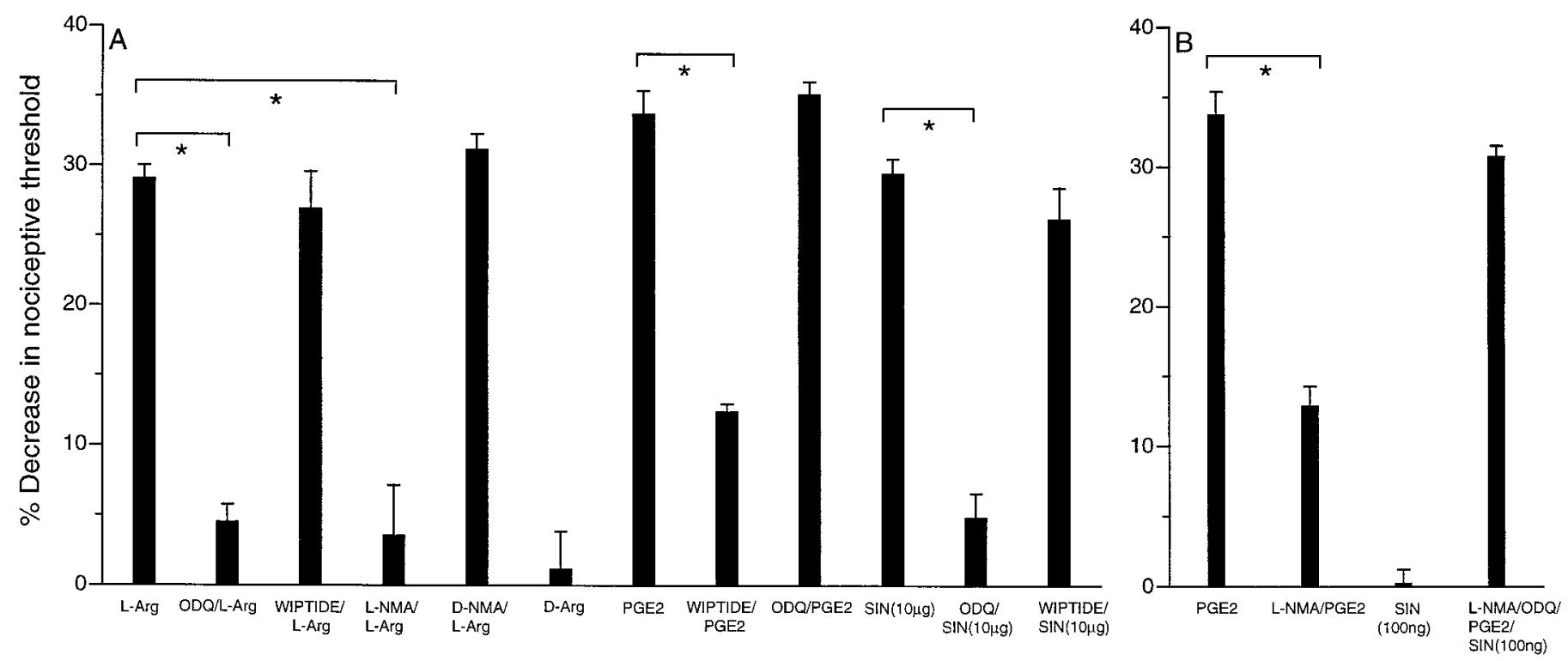

Figure 6. $A$, Change in mechanical paw withdrawal after injection of L-Arg $(L-A r g)(10 \mu \mathrm{g} ; n=12)$, ODQ plus L-Arg $(O D Q / L-A r g)(n=6), \mathrm{WIPTIDE}$ plus L-Arg $(W I P T I D E / L-A r g)(n=6), \mathrm{L}-\mathrm{NMA}$ plus L-Arg $(L-N M A / L-A r g)(n=6), \mathrm{D}-\mathrm{NMA} / \mathrm{L}-\mathrm{Arg}(n=6), \mathrm{D}-\mathrm{Arg}(D-A r g)(10 \mu \mathrm{g} ; n=6), \mathrm{PGE} 2(P G E 2)$ $(n=12)$, WIPTIDE plus PGE 2 (WIPTIDE/PGE2) $(n=12)$, ODQ plus PGE 2 (ODQ/PGE2) $(n=8), S I N-1(10 \mu \mathrm{g} ; n=6)$, ODQ plus SIN-1 $(O D Q / S I N)$ $(n=8)$, and WIPTIDE plus SIN-1 $($ WIPTIDE/SIN $)(n=6) . B$, Change in mechanical paw-withdrawal threshold after injection of PGE $2(n=12)$, L-NMA plus $\mathrm{PGE}_{2}(L-N M A / P G E 2)(n=6), \mathrm{SIN}-1(S I N)(100 \mathrm{ng} ; n=6)$, and L-NMA plus ODQ plus PGE 2 plus SIN-1 $(L-N M A / O D Q / P G E 2 / S I N)(100$ ng; $n=12)$.

cells parallels the effect of L-NMA on $\mathrm{PGE}_{2}$-induced hyperalgesia, suggesting that both phenomena depend on NO for full expression and that cells other than the one being recorded from are not required for these effects of $\mathrm{PGE}_{2}$ or NO. Although many effects of NO have been reported to be mediated by guanylyl cyclase activity (Jaffrey and Snyder, 1995), we observed that the guanylyl cyclase inhibitor ODQ had no effect on $\mathrm{PGE}_{2}$-induced hyperalgesia, suggesting that facilitation of $\mathrm{PGE}_{2}$-induced hyperalgesia by $\mathrm{NO}$ and the other mechanisms of $\mathrm{PGE}_{2}$-induced hyperalgesia do not involve NO signaling through guanylyl cyclase.

Additional experiments attempted to determine where NO might act to facilitate $\mathrm{PGE}_{2}$ hyperalgesia. Evidence suggests that initiation of $\mathrm{PGE}_{2}$-induced hyperalgesia is attributable to action of $\mathrm{PGE}_{2}$ at an E-type prostaglandin receptor on the primary afferent nociceptor terminal, activation of a stimulatory G-protein which then activates adenylyl cyclase, followed by an increase in the level of cAMP and activation of PKA (Taiwo and Levine, 1989, 1991; Khasar et al., 1995). We observed that hyperalgesia produced by 8-bromo-cAMP (which activates PKA) and forskolin (which activates adenylyl cyclase) was attenuated by L-NMA in a manner similar to the effect of L-NMA on $\mathrm{PGE}_{2}$ hyperalgesia, but that in contrast, hyperalgesia produced by injection of PKACS (to mimic activity of endogenous PKA) was not affected by L-NMA. These results suggest that NO might be required for activation of $\mathrm{PKA}$ after administration of $\mathrm{PGE}_{2}$. Of note, others have shown that NO can modulate activity of kinases (Gopalakrishna et al., 1993; Burgstahler and Nathanson, 1995; Studer et al., 1996; Minamino et al., 1997). The fact that L-NMA inhibited hyperalgesia induced by two other direct-acting hyperalgesic agents (CGS21680, an $\mathrm{A}_{2}$ adenosine receptor agonist, and 8-OH-DPAT, a $5 \mathrm{HT}_{1 \mathrm{~A}}$ serotonin receptor agonist) suggests that dependence on NO is a general feature of hyperalgesia induced via the cAMP second messenger system.

Additional experiments revealed that there was an independent NO-induced hyperalgesia that depended on the cGMP second messenger pathway and not on the cAMP pathway (Fig. $6 B$ ). We hypothesize that a relatively low level of NO can facilitate cAMPdependent hyperalgesia induced by $\mathrm{PGE}_{2}$ and other inflammatory mediators, whereas stimulated increases in NO to higher levels might be required to induce the cGMP-dependent hyperalgesia. Supporting this hypothesis, when endogenous NO production was blocked, the level of NO donor required to facilitate $\mathrm{PGE}_{2}$-induced hyperalgesia was at least an order of magnitude lower than the level required for NO to induce hyperalgesia by itself. However, it is not possible to know whether exogenous NO has ready access to the necessary sites. Also, we cannot determine from our data whether basal levels of constitutively synthesized $\mathrm{NO}$ are sufficient to facilitate $\mathrm{PGE}_{2}$-induced hyperalgesia or whether $\mathrm{PGE}_{2}$ stimulates synthesis of $\mathrm{NO}$ (to a level lower than that required to induce cGMP-dependent hyperalgesia). However, it appears that constitutive synthesis of NO does not affect baseline nociceptive threshold, because inhibition of NOS does not alter paw-withdrawal threshold. Finally, although our in vitro patch-clamp data imply that the $\mathrm{NO}$ that facilitates $\mathrm{PGE}_{2}$-induced hyperalgesia is synthesized in DRG neurons and acts on DRG neurons, our data do not determine the site of action for cGMPdependent NO-induced hyperalgesia. Clearly, further study is needed to determine concentration and site requirements for the two distinct effects of NO that we have evaluated.

$\mathrm{NO}$ is generated in significant concentrations at sites of inflammation in which multiple hyperalgesic inflammatory mediators, such as $\mathrm{PGE}_{2}$, adenosine, or serotonin, are also produced. Although the evidence for a role of NO in clinical pain is limited, NO may facilitate the hyperalgesia induced by those mediators using the cAMP second messenger pathway and may also have an independent cGMP-dependent hyperalgesic effect. If both of these contributions are clinically significant, different therapies for these two distinct mechanisms of NO may be needed for successful pharmacological treatment of inflammatory pain. 


\section{REFERENCES}

Aley KO, Levine JD (1997a) Different mechanisms mediate development and expression of tolerance and dependence for peripheral muopioid antinociception in rat. J Neurosci 17:8018-8023.

Aley KO, Levine JD (1997b) Dissociation of tolerance and dependence for opioid peripheral antinociception in rats. J Neurosci 17:3907-3912.

Beesley JE (1995) Histochemical methods for detecting nitric oxide synthase. Histochem J 27:757-769.

Burgstahler AD, Nathanson MH (1995) NO modulates the apicolateral cytoskeleton of isolated hepatocytes by a PKC-dependent, cGMPindependent mechanism. Am J Physiol 269:G789-G799.

Choi Y, Raja SN, Moore LC, Tobin JR (1996) Neuropathic pain in rats is associated with altered nitric oxide synthase activity in neural tissue. J Neurol Sci 138:14-20.

Collier HO, Schneider C (1972) Nociceptive response to prostaglandins and analgesic actions of aspirin and morphine. Nat New Biol 236:141-143.

Davis KD, Meyer RA, Campbell JN (1993) Chemosensitivity and sensitization of nociceptive afferents that innervate the hairy skin of monkey. J Neurophysiol 69:1071-1081.

Dymshitz J, Vasko MR (1994) Nitric oxide and cyclic guanosine 3',5'monophosphate do not alter neuropeptide release from rat sensory neurons grown in culture. Neuroscience 62:1279-1286.

England S, Bevan S, Docherty RJ (1996) PGE2 modulates the tetrodotoxin-resistant sodium current in neonatal rat dorsal root ganglion neurones via the cyclic AMP-protein kinase A cascade. J Physiol (Lond) 495:429-440.

Farkas-Szallasi T, Lundberg JM, Wiesenfeld HZ, Hokfelt T, Szallasi A (1995) Increased levels of GMAP, VIP and nitric oxide synthase, and their mRNAs, in lumbar dorsal root ganglia of the rat following systemic resiniferatoxin treatment. NeuroReport 6:2230-2234.

Ferreira SH, Nakamura M, Castro MSA (1978) The hyperalgesic effects of prostacyclin and prostaglandin E2. Prostaglandins 16:31-37.

Fiallos-Estrada CE, Kummer W, Mayer B, Bravo R, Zimmerman M, Herdegen T (1993) Long-lasting increase of nitric oxide synthase immunoreactivity, NADPH-diaphorase reaction and c-JUN coexpression in rat dorsal root ganglion neurons following sciatic nerve transection. Neurosci Lett 150:169-173.

Gold MS, Reichling DB, Shuster MJ, Levine JD (1996a) Hyperalgesic agents increase a tetrodotoxin-resistant $\mathrm{Na}^{+}$current in nociceptors. Proc Natl Acad Sci USA 93:1108-1112.

Gold MS, Dastmalchi S, Levine JD (1996b) Co-expression of nociceptor properties in dorsal root ganglion neurons from the adult rat in vitro. Neuroscience 71:265-275.

Gopalakrishna R, Chen ZH, Gundimeda U (1993) Nitric oxide and nitric oxide-generating agents induce a reversible inactivation of protein kinase $\mathrm{C}$ activity and phorbol ester binding. J Biol Chem 268:27180-27185.

Harvey JS, Burgess GM (1996) Cyclic GMP regulates activation of phosphoinositidase $\mathrm{C}$ by bradykinin in sensory neurons. Biochem J 539-544.

Holthusen H, Arndt JO (1994) Nitric oxide evokes pain in humans on intracutaneous injection. Neurosci Lett 165:71-74.

Holthusen H, Arndt JO (1995) Nitric oxide evokes pain at nociceptors of the paravascular tissue and veins in humans. J Physiol (Lond) 487:253-258.

Jaffrey SR, Snyder SH (1995) Nitric oxide: a neural messenger. Annu Rev Cell Dev Biol 11:417-440.

Khasar SG, Wang JF, Taiwo YO, Heller PH, Green PG, Levine JD (1995) Mu-opioid agonist enhancement of prostaglandin-induced hyperalgesia in the rat: a G-protein beta gamma subunit-mediated effect? Neuroscience 67:189-195.

Lawand NB, Willis WD, Westlund KN (1997) Blockade of joint inflammation and secondary hyperalgesia by L-NAME, a nitric oxide synthase inhibitor. NeuroReport 8:895-899.

Majewski M, Sienkiewicz W, Kaleczyc J, Mayer B, Czaja K, Lakomy M (1995) The distribution and co-localization of immunoreactivity to nitric oxide synthase, vasoactive intestinal polypeptide and substance $\mathrm{P}$ within nerve fibres supplying bovine and porcine female genital organs. Cell Tissue Res 281:445-464.

Martin HA, Basbaum AI, Kwiat GC, Goetzl EJ, Levine JD (1987) Leukotriene and prostaglandin sensitization of cutaneous highthreshold C-mechanonociceptors in the rat. Neuroscience 22:651-659.

Minamino T, Kitakaze M, Node K, Funaya H, Hori M (1997) Inhibition of nitric oxide synthesis increases adenosine production via an extra- cellular pathway through activation of protein kinase C. Circulation 96:1586-1592.

Moncada S, Ferreira SH, Vane JR (1975) Inhibition of prostaglandin biosynthesis as the mechanism of analgesia of aspirin-like drugs in the dog knee joint. Eur J Pharmacol 31:250-260.

Moore PK, Wallace P, Gaffen Z, Hart SL, Babbedge RC (1993) Characterization of the novel nitric oxide synthase inhibitor 7-nitro indazole and related indazoles: antinociceptive and cardiovascular effects. Br J Pharmacol 110:219-224.

Moulton PJ (1996) Inflammatory joint disease: the role of cytokines, cyclooxygenases and reactive oxygen species. $\mathrm{Br} \mathrm{J}$ Biomed Sci 53:317-324.

Ouseph AK, Khasar SG, Levine JD (1995) Multiple second messenger systems act sequentially to mediate rolipram-induced prolongation of prostaglandin E2-induced mechanical hyperalgesia in the rat. Neuroscience 64:769-776.

Qian Y, Chao DS, Santillano DR, Cornwell TL, Nairn AC, Greengard P, Lincoln TM, Bredt DS (1996) cGMP-dependent protein kinase in dorsal root ganglion: relationship with nitric oxide synthase and nociceptive neurons. J Neurosci 16:3130-3138.

Ren K, Ruda MA (1995) Nitric oxide synthase-containing neurons in sensory ganglia of the rat are susceptible to capsaicin-induced cytotoxicity. Neuroscience 65:505-511.

Robbins R A, Grisham MB (1997) Nitric oxide. Int J Biochem Cell Biol 29:857-860.

Rueff A, Dray A (1993) Sensitization of peripheral afferent fibers in the in vitro neonatal rat spinal cord-tail by bradykinin and prostaglandins. Neuroscience 54:527-535.

Schaible HG, Schmidt RF (1988) Excitation and sensitization of fine articular afferents from cat's knee joint by prostaglandin E2. J Physiol (Lond) 403:91-104.

Steel JH, Terenghi G, Chung JM, Na HS, Carlton SM, Polak JM (1994) Increased nitric oxide synthase immunoreactivity in rat dorsal root ganglia in a neuropathic pain model. Neurosci Lett 169:81-84.

Studer RK, DeRubertis FR, Craven PA (1996) Nitric oxide suppresses increases in mesangial cell protein kinase $\mathrm{C}$, transforming growth factor beta, and fibronectin synthesis induced by thromboxane. J Am Soc Nephrol 7:999-1005.

Taiwo YO, Levine JD (1989) Prostaglandin effects after elimination of indirect hyperalgesic mechanisms in the skin of the rat. Brain Res 492:397-399.

Taiwo YO, Levine JD (1990) Direct cutaneous hyperalgesia induced by adenosine. Neuroscience 38:757-762.

Taiwo YO, Levine JD (1991) Further confirmation of the role of adenyl cyclase and of cAMP-dependent protein kinase in primary afferent hyperalgesia. Neuroscience 44:131-135.

Taiwo YO, Levine JD (1992) Serotonin is a directly acting hyperalgesic agent in the rat. Neuroscience 48:485-490.

Taiwo YO, Heller PH, Levine JD (1992) Mediation of serotonin hyperalgesia by the cAMP second messenger system. Neuroscience 48:479-483.

Thomas DA, Ren K, Besse D, Ruda MA, Dubner R (1996) Application of nitric oxide synthase inhibitor, $N$-nitro-L-arginine methyl ester, on injured nerve attenuates neuropathy-induced thermal hyperalgesia in rats. Neurosci Lett 210:124-126.

Vanhatalo S, Klinge E, Sjostrand NO, Soinila S (1996) Nitric oxidesynthesizing neurons originating at several different levels innervate rat penis. Neuroscience 75:891-899.

Vizzard MA, Erdman SL, deGroat GW (1995) Increased expression of neuronal nitric oxide synthase in dorsal root ganglion neurons after systemic capsaicin administration. Neuroscience 67:1-5.

Vizzard MA, Erdman SL, deGroat GW (1996) Increased expression of neuronal nitric oxide synthase in bladder afferent pathways following chronic bladder irritation. J Comp Neurol 370:191-202.

Wallace JL, Chin BC (1997) Inflammatory mediators in gastrointestinal defense and injury. Proc Soc Exp Biol Med 214:192-203.

Wiesenfeld-Hallin Z, Hao JX, Xu XJ, Hokfelt T (1993) Nitric oxide mediates ongoing discharges in dorsal root ganglion cells after peripheral nerve injury. J Neurophysiol 70:2350-2353.

Zhang X, Verge V, Wiesenfeld-Hallin Z, Ju G, Bredt D, Synder SH, Hokfelt T (1993) Nitric oxide synthase-like immunoreactivity in lumbar dorsal root ganglia and spinal cord of rat and monkey and effect of peripheral axotomy. J Comp Neurol 335:563-575. 